\title{
2D Transition Metal Dichalcogenides and Graphene-Based Ternary Composites for Photocatalytic Hydrogen Evolution and Pollutants Degradation
}

\author{
Ying Chen ${ }^{1,3}$, Hongqi Sun ${ }^{2, *}$ and Wenchao Peng ${ }^{1, *}$ \\ 1 School of Chemical Engineering and Technology, Tianjin University, Tianjin 300072, China; \\ yingchen@tju.edu.cn \\ 2 School of Engineering, Edith Cowan University, 270 Joondalup Drive, Joondalup, Perth, WA 6027, Australia \\ 3 Department of Chemical Engineering, Renai College of Tianjin University, Tianjin 301636, China \\ * Correspondence: h.sun@ecu.edu.au (H.S.); wenchao.peng@tju.edu.cn (W.P.); Tel.: +86-22-85356119 (W.P.) \\ Academic Editor: Hermenegildo García \\ Received: 26 January 2017; Accepted: 8 March 2017; Published: 15 March 2017
}

\begin{abstract}
Photocatalysis have attracted great attention due to their useful applications for sustainable hydrogen evolution and pollutants degradation. Transition metal dichalcogenides (TMDs) such as $\mathrm{MoS}_{2}$ and $\mathrm{WS}_{2}$ have exhibited great potential as cocatalysts to increase the photo-activity of some semiconductors. By combination with graphene (GR), enhanced cocatalysts of TMD/GR hybrids could be synthesized. GR here can act as a conductive electron channel for the transport of the photogenerated electrons, while the TMDs nanosheets in the hybrids can collect electrons and act as active sites for photocatalytic reactions. This mini review will focus on the application of TMD/GR hybrids as cocatalysts for semiconductors in photocatalytic reactions, by which we hope to provide enriched information of TMD/GR as a platform to develop more efficient photocatalysts for solar energy utilization.
\end{abstract}

Keywords: transition metal dichalcogenides (TMDs); graphene; photocatalytic; hydrogen evolution; pollutants degradation

\section{Introduction}

Since the discovery of the photocatalytic splitting of water on $\mathrm{TiO}_{2}$ electrodes by Fujishima and Honda in 1972 [1], photocatalysis has attracted great attention for eliminating hazardous pollutants and generating sustainable energy [2]. Semiconductors such as $\mathrm{TiO}_{2}, \mathrm{ZnO}, \mathrm{CdS}$, etc. can act as photocatalysts for the utilization of solar energy [3]. They are however limited in real application by the rapid electron-hole recombination [4-6]. Noble metal cocatalysts are usually loaded to enhance the activity of the semiconductor photocatalysts [7]. However, these metals are rare and expensive to apply [8]. The development of highly active and low cost cocatalysts remains a great challenge in the field of photocatalysis.

Transition metal dichalcogenides (TMDs) such as $\mathrm{MoS}_{2}$ and $\mathrm{WS}_{2}$ have exhibited excellent activities as cocatalysts for the modification of semiconductors $[8,9]$. The properties of TMDs can be tailored according to their crystalline structure and the number and stacking sequence of their nanosheets [10-14]. By loading TMDs cocatalysts, semiconductor-semiconductor or metal-semiconductor junctions will form, and more interfaces could be created $[15,16]$. Charge separation and electron transport can therefore be enhanced, leading to the activity improvement [15]. Furthermore, many kinds of TMDs with different phases were reported to be active for the electrochemical hydrogen evolution reaction (HER), which stems from their exposed and 
under-coordinated edge sites [17-19]. Therefore, loading the TMDs as cocatalysts for semiconductors could also lower the activation energy and overpotential for photocatalytic $\mathrm{H}_{2}$ evolution [8]. On the other hand, TMDs have special 2D layered structure, and can be used as effective supports for anchor of semiconductor nanoparticles, which could reduce the mobility, provide more active sites, and avoid coalescence and agglomeration of the semiconductors [20-22]. Based on the above analysis, TMDs have shown great potential as substitute of noble metal cocatalysts for the synthesis of composite photocatalysts with high activity [8].

Graphene (GR) consists of a single layer and $\mathrm{sp}^{2}$-hybridized carbon lattice with excellent electrical $\left(200,000 \mathrm{~cm}^{2} \cdot \mathrm{V}^{-1} \cdot \mathrm{s}^{-1}\right)$, thermal, and mechanical properties, and is a novel material that has emerged as a rapidly rising star in the field of material science [23]. The photocatalytic activity of semiconductors can be greatly increased by loading GR as cocatalyst, mainly owing to the effective separation of the electron-hole pairs [24,25].

By combining GR with TMDs, new hybrid cocatalysts could be synthesized with 2D layered structures. GR here can transport the photogenerated electrons rapidly, and the TMDs in the hybrids can accept electrons and act as active sites for $\mathrm{H}_{2}$ evolution or radicals generation. This mini review will focus on the synthesis methods of TMD/GR-based photocatalysts and their applications for photocatalytic $\mathrm{H}_{2}$ evolution and organic pollutants degradation. Based on this review, we hope to offer enriched information of TMD/GR as a platform to fabricate more efficient photocatalysts for solar energy utilization.

\section{TMD/GR-Based Composites for Photocatalytic $\mathbf{H}_{2}$ Evolution}

$\mathrm{TiO}_{2}$ is the most frequently used semiconductor for photocatalytic $\mathrm{H}_{2}$ evolution, which can only absorb and utilize UV light due to its large band gap (3.2 eV) [26]. Xiang et al. synthesized ternary composites consisting of $\mathrm{TiO}_{2}$ nanoparticles grown on the $\mathrm{MoS}_{2} / \mathrm{GR}$ hybrid as enhanced photocatalysts for $\mathrm{H}_{2}$ evolution (Figure 1) [25]. The $\mathrm{TiO}_{2}-\mathrm{MoS}_{2} / \mathrm{GR}$ composites were prepared using a two-step hydrothermal method. As shown in Figure 1, the $\mathrm{TiO}_{2}$ nanoparticles were supported on the $2 \mathrm{D} \mathrm{MoS} / \mathrm{GR}$ hybrid uniformly with intimate contact. The electrons can therefore transfer rapidly from $\mathrm{TiO}_{2}$ to the $\mathrm{MoS}_{2} / \mathrm{GR}$ cocatalyst, and the charge recombination can therefore be suppressed. The activity of the ternary composites can be tuned by adjusting the GR percentage of $\mathrm{MoS}_{2} / \mathrm{GR}$ cocatalysts and the percentage of the $\mathrm{MoS}_{2} / \mathrm{GR}$ hybrid for the ternary photocatalysts. The optimized $\mathrm{TiO}_{2}-\mathrm{MoS}_{2} / \mathrm{GR}$ composite could obtain a high $\mathrm{H}_{2}$ evolution rate of $165.3 \mu \mathrm{mol} \cdot \mathrm{h}^{-1}$ and a quantum efficiency of $9.7 \%$ at $365 \mathrm{~nm}$.
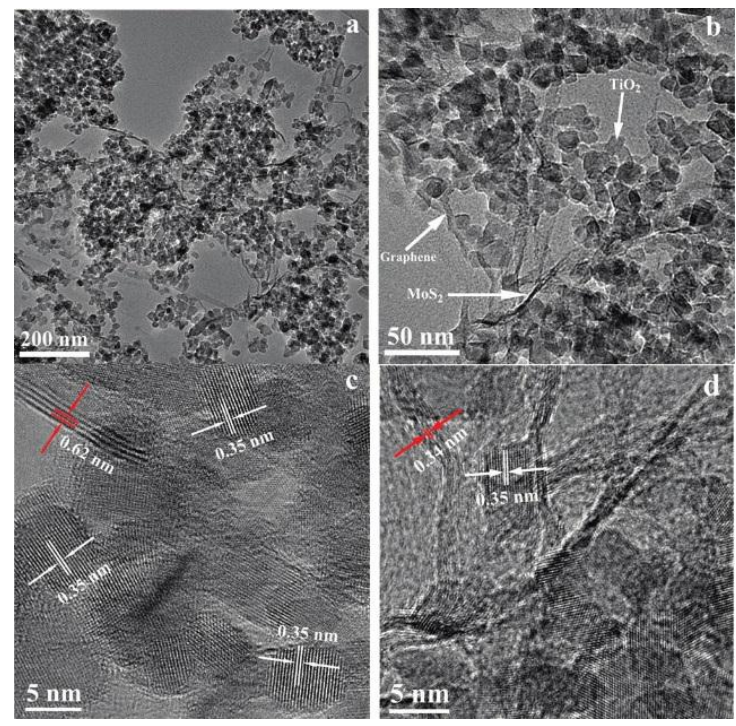

Figure 1. Morphology characterization of the $\mathrm{TiO}_{2}-\mathrm{MoS}_{2} /$ graphene (GR) composite. (a,b) Transmission electron microscopy (TEM) and (c,d) high-resolution TEM (HRTEM) images of the $\mathrm{TiO}_{2}-\mathrm{MoS}_{2} / \mathrm{GR}$ composite (reprinted from [25] with permission, Copyright American Chemical Society, 2012). 
$\mathrm{CdS}$ has a narrow bandgap of $2.3 \mathrm{eV}$, which is effective for capturing the visible light [36]. Chang et al. used nanosized GR as support for the growth of $\mathrm{MoS}_{2} ; 3 \mathrm{D}$ hierarchical CdS-MoS $/$ GR composites with diameters of 100-300 nm were then synthesized with the help of polyvinylpyrrolidone (PVP) (Figure 2) [27]. As shown in Figure 2e, the $\mathrm{MoS}_{2}$ sheets on nanosized GR have many defect sites and disordered structures due to the low synthesis temperature, CdS nanoparticles can then firmly anchor on these defects and vacancies (Figure $2 \mathrm{~g}-\mathrm{j}$ ). After optimizing each component proportion, the highest $\mathrm{H}_{2}$ evolution rate could be as large as $1.8 \mathrm{mmol} / \mathrm{h}$ with an apparent quantum efficiency (AQE) of $28.1 \%$ at $420 \mathrm{~nm}$, which was even higher than that of $\mathrm{Pt} / \mathrm{CdS}$. They thought that the activities of $\mathrm{S}$ atoms in the $\mathrm{MoS}_{2}$ molecules were different with respect to their different coordination (Figure 3a). Unsaturated $\mathrm{S}$ atoms are active for $\mathrm{H}^{+}$adsorption and reduction (Figure $3 \mathrm{~b}$ ), while the saturated $S$ atoms on the basal plane are inert. The nanosized few-layer $\mathrm{MoS}_{2}$ supported on GR has more exposed edges and unsaturated active $S$ atoms, which is therefore a promising cocatalyst for the activity enhancement of CdS.

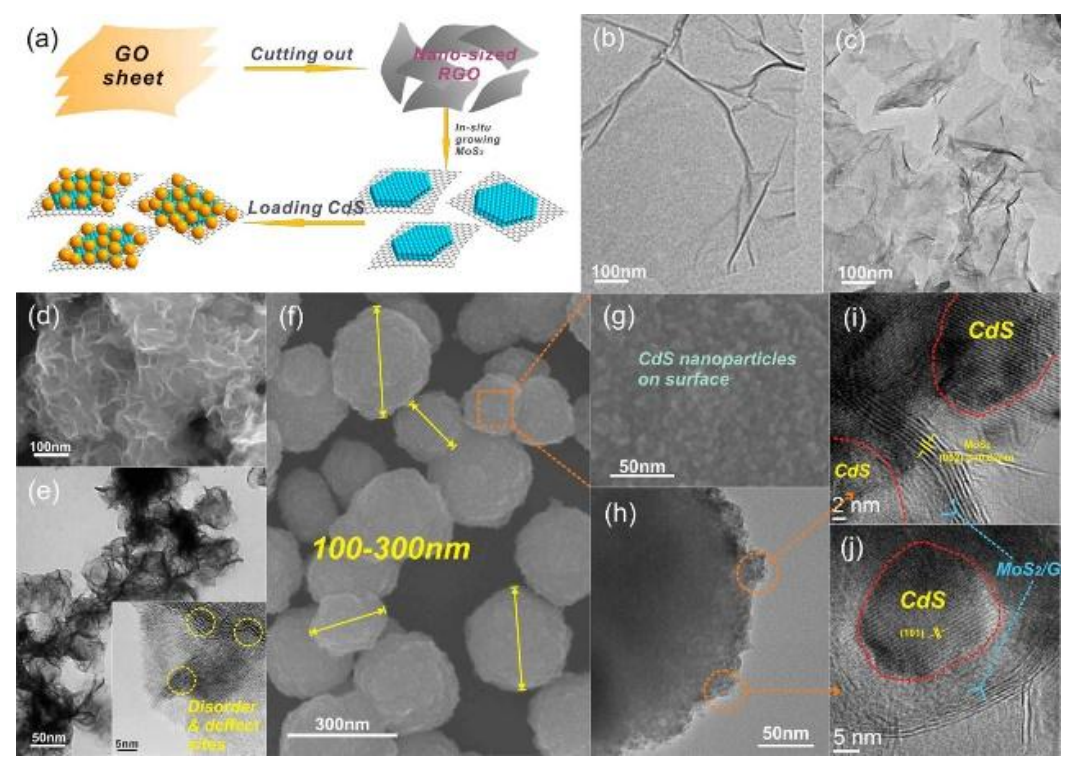

Figure 2. (a) Schematic illustration of growth mechanism of $\mathrm{MoS}_{2}$ /GR-CdS composites; TEM images of (b) graphene oxide (GO) and (c) nanosized graphene (GR); (d) Scanning electron microscopy (SEM) and (e) TEM images of as-prepared $\mathrm{MoS}_{2} /$ GR composite; the inset of (e) is the HRTEM image of $\mathrm{MoS}_{2} / \mathrm{GR}$ composite; ( $\mathbf{f}$ and $\mathbf{g}$ ) SEM images of CdS-MoS $/$ /GR composites; (h) TEM and (i and $\mathbf{j}$ ) HRTEM images of the CdS- $\mathrm{MoS}_{2} / \mathrm{GR}$ composite (reprinted from [27] with permission, Copyright American Chemical Society, 2014).
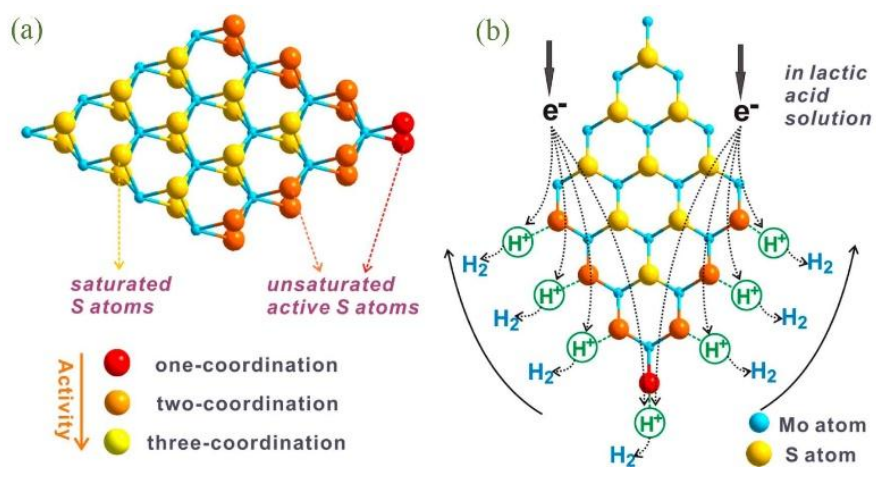

Figure 3. (a) Schematic illustration of the microstructure of $\mathrm{MoS}_{2}$ and (b) its cocatalytic mechanism of $\mathrm{H}_{2}$ generation in lactic acid solution (reprinted from [27] with permission, Copyright American Chemical Society, 2014). 
Xiang et al. synthesized CdS-WS 2 /GR ternary composites for photocatalytic $\mathrm{H}_{2}$ evolution [32] The optimized $\mathrm{WS}_{2} / \mathrm{GR}$ content in the ternary $\mathrm{CdS}-\mathrm{WS}_{2} / \mathrm{GR}$ composites was determined to be 4.2 wt \%. Using $0.35 \mathrm{M} \mathrm{Na}_{2} \mathrm{~S} / 0.25 \mathrm{M} \mathrm{Na}_{2} \mathrm{SO}_{3}$ as sacrificial agent, a satisfactory $\mathrm{H}_{2}$ evolution rate of $1.842 \mathrm{mmol} \cdot \mathrm{h}^{-1} \cdot \mathrm{g}^{-1}$ could be achieved with an apparent quantum efficiency of $21.2 \%$ at $420 \mathrm{~nm}$. The transient photocurrent response was also enhanced by loading the $\mathrm{WS}_{2} / \mathrm{GR}$ cocatalyst, which was promising evidence for the improved charge transport (Figure 4). By loading WS 2 /GR cocatalyst, more active sites will be introduced, and charge separation and interfacial charge transfer could be enhanced, thus leading to the greatly increased photo-activity.

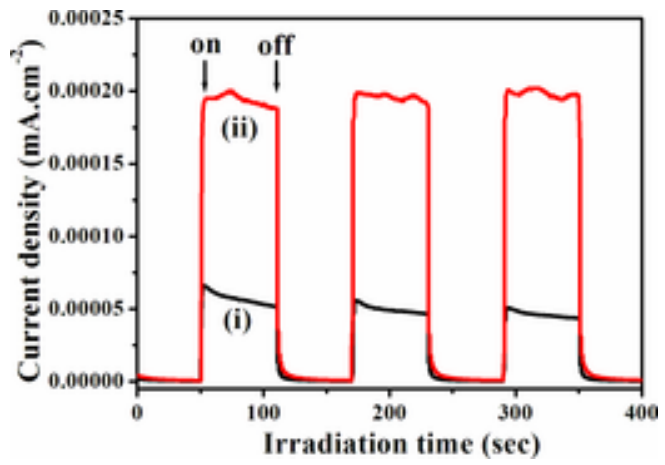

Figure 4. Transient photocurrent responses of pure $\mathrm{CdS}$ and $\mathrm{CdS}-\mathrm{WS}_{2} / \mathrm{GR}$ composite in $1 \mathrm{M} \mathrm{Na}_{2} \mathrm{SO}_{4}$ aqueous solution under visible-light irradiation at $0.5 \mathrm{~V}$ versus $\mathrm{Ag} / \mathrm{AgCl}$ (reprinted from [32] with permission, Copyright Wiley-VCH, 2016).

(a)

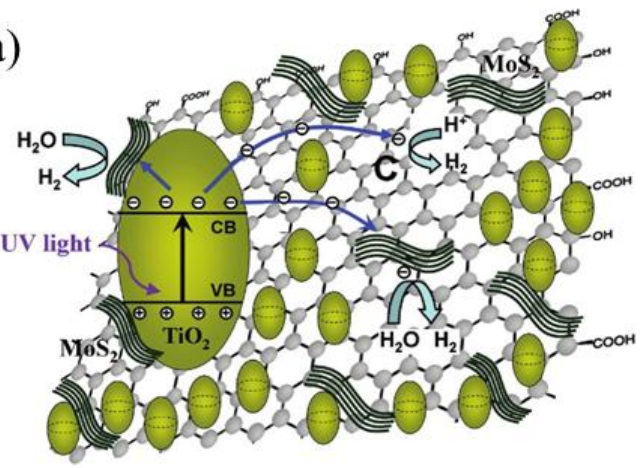

(c)

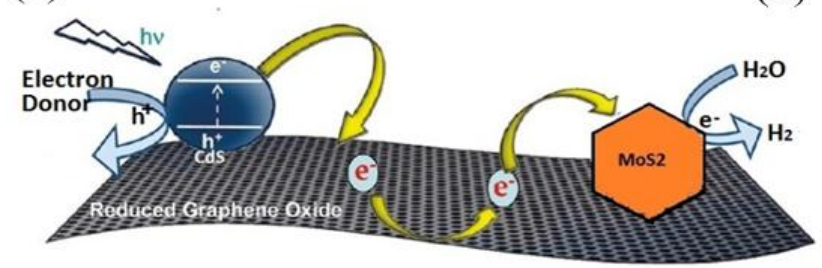

(b)

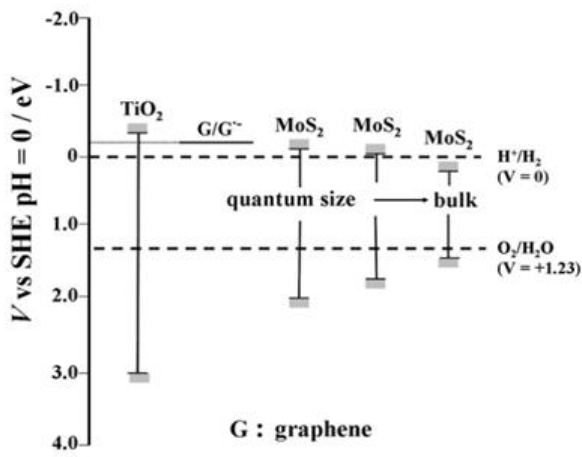

(d)

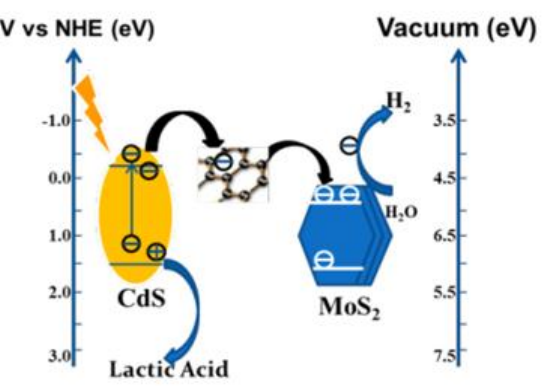

Figure 5. Schematic illustration of (a) the charge transfer in $\mathrm{TiO}_{2}-\mathrm{MoS}_{2} / \mathrm{GR}$ composites for photocatalytic $\mathrm{H}_{2}$ evolution; and (b) the potential and band positions in the $\mathrm{TiO}_{2} / \mathrm{MoS}_{2}$ /graphene system (reprinted from [25] with permission, Copyright American Chemical Society, 2012); (c) Graphene-supported $\mathrm{CdS}$ and $\mathrm{MoS}_{2}$ for photocatalytic hydrogen evolution; (d) The band positions for the CdS-graphene- $\mathrm{MoS}_{2}$ system (reprinted from [28] with permission, Copyright Royal Society of Chemistry, 2014). (SHE: Standard hydrogen electrode; NHE: Normal hydrogen electrode). 
During the photocatalytic $\mathrm{H}_{2}$ evolution process, the metal oxide can absorb a photon to create an electron-hole pair with irradiation (Figure $5 \mathrm{a}, \mathrm{c}$ ). Both of the graphene/ graphene ${ }^{\bullet-}$ redox potential and conduction band (CB) of quantum-sized $\mathrm{MoS}_{2}$ are slightly lower than the $\mathrm{CB}$ of anatase $\mathrm{TiO}_{2}$ or CdS (Figure 4b,d). Part of the excited electrons can then directly transfer to active sites of $\mathrm{MoS}_{2}$, and another part transfer to active sites of $\mathrm{MoS}_{2}$ via graphene conducting channel. Graphene here can act as a "highway" for the rapid transport of photo-generated electrons, while $\mathrm{MoS}_{2}$ nanosheets can accept electrons and act as active sites for $\mathrm{H}_{2}$ evolution. Therefore, using $\mathrm{MoS}_{2} / \mathrm{GR}$ hybrid as cocatalyst, suppression of charge recombination, improvement of interfacial charge transfer, and an increase in the number of active sites could be achieved, thus leading to the enhanced photo-activity.

It has been reported that sub-10 $\mathrm{nm}$ rutile $\mathrm{TiO}_{2}$ with $1 \mathrm{wt} \% \mathrm{Pt}$ doping exhibited state-of-the-art activity among $\mathrm{TiO}_{2}$-based composites for photocatalytic water splitting. The hydrogen evolution rate could be achieved to $932 \mathrm{mmol} \cdot \mathrm{h}^{-1} \cdot \mathrm{g}^{-1}$ under visible light $\left(>400 \mathrm{~nm}\right.$ ) and $1954 \mathrm{mmol} \cdot \mathrm{h}^{-1} \cdot \mathrm{g}^{-1}$ under simulated solar light [37]. By loading $0.30 \mathrm{wt} \%$ of $\mathrm{Pt}$ and $0.13 \mathrm{wt} \%$ of $\mathrm{PdS}$ as cocatalysts on $\mathrm{CdS}$, another CdS-based state-of-the-art material could be synthesized with a quantum efficiency (QE) up to $93 \%$ and a hydrogen evolution rate of $8.77 \mathrm{mmol} \cdot \mathrm{h}^{-1}$ [38]. Compared to these state-of-the-art materials, the activities of TMD/GR modified semiconductors are relatively weak, with lower $\mathrm{H}_{2}$ evolution rates and QEs. Although the TMD/GR cocatalysts are more cost effective, deep studies are still needed to obtain higher efficiencies for real application.

\section{TMD/GR-Based Photocatalysts for Pollutants Degradation}

Photocatalysis is also an attractive technology for the degradation of pollutants in water using solar energy [39]. Han et al. used a hydrothermal method to combine the exfoliated $\mathrm{MoS}_{2}, \mathrm{GR}$ and TiO 2 P25 together [40]. The obtained composite was a novel graphene-based three-dimensional (3D) aerogel embedded with $\mathrm{TiO}_{2}$ particles and $\mathrm{MoS}_{2}$ nanosheets (Figure 6). Porous structure could be observed with pore sizes of about several micrometers (Figure 6b). The Nyquist plots of the samples were also tested, and the final 3D GR-MoS $2-\mathrm{TiO}_{2}$ composite had the smallest cure radius (Figure 7), indicating that the addition of 3D graphene aerogel can decrease the solid state interface layer resistance and the charge transfer resistance. During the application test, the final composite had better adsorption ability for methyl orange (MO) due to the maximization of accessible sites of the 3D interconnected networks (Figure 8a). The 3D photocatalyst was proved to be very effective for the photocatalytic degradation of $\mathrm{MO}$, and nearly no $\mathrm{MO}$ was left after 15 min irradiation (Figure 8b).
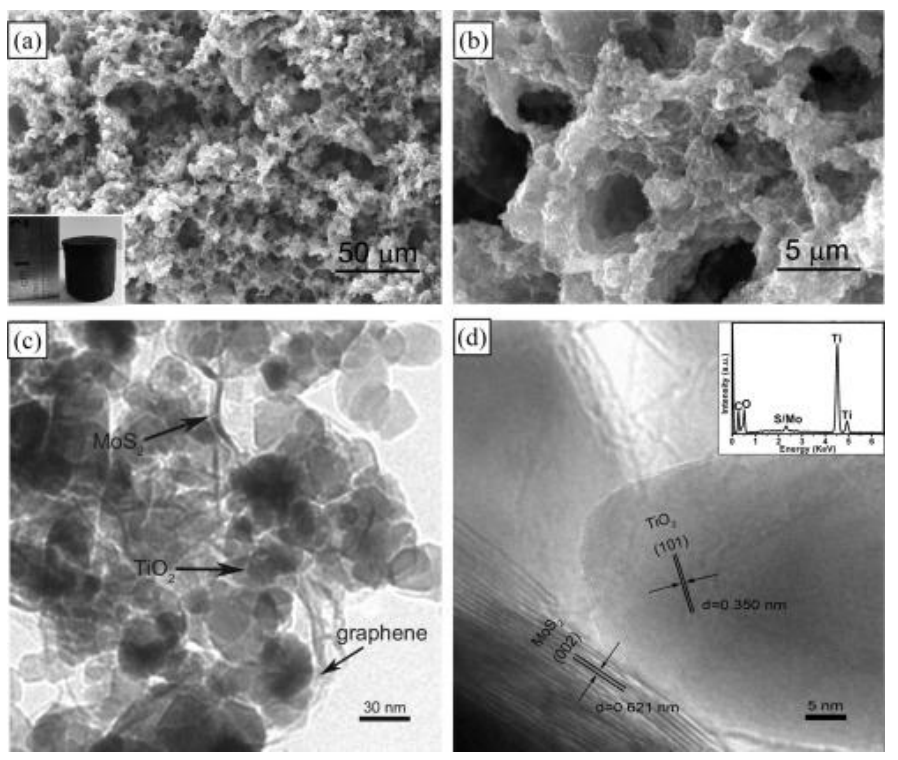

Figure 6. (a,b) SEM images of the as-prepared $\mathrm{MoS}_{2} / \mathrm{P} 25 / \mathrm{GR}$-aerogel; the inset image is a digital photo of the free-standing $\mathrm{MoS}_{2} / \mathrm{P} 25 / \mathrm{GR}$-aerogel. (c,d) TEM images and energy-dispersive X-ray spectroscopy (EDS) (insert) pattern of the as-prepared $\mathrm{MoS}_{2} / \mathrm{P} 25 / \mathrm{GR}$-aerogel (reprinted from [40] with permission, Copyright Elsevier, 2014). 


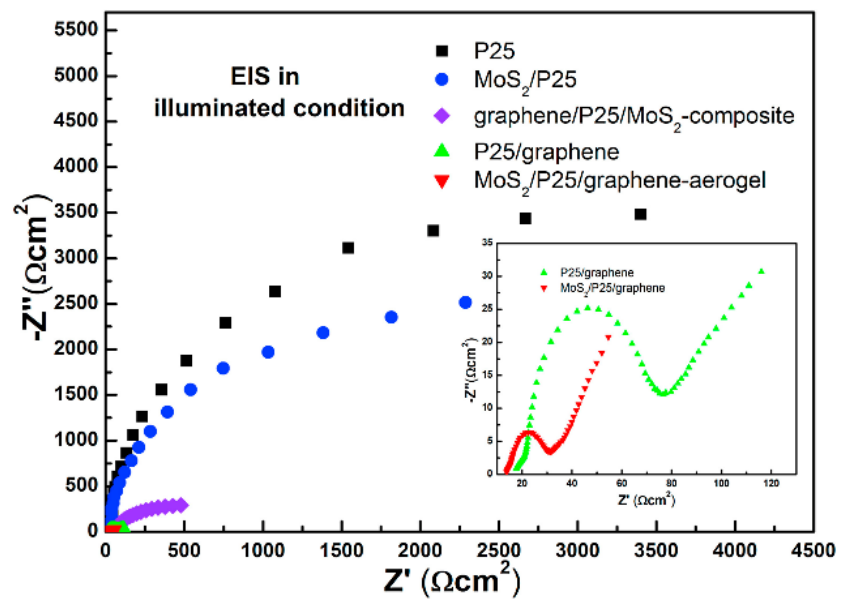

Figure 7. Electrochemical impedance spectroscopy (EIS) Nyquist plots of $\mathrm{MoS}_{2} / \mathrm{P} 25 / \mathrm{GR}$-aerogel, GR/P25/MoS 2 -composite, P25/GR, $\mathrm{MoS}_{2} /$ P25, and P25 nanoparticles in sulfide-sulfite electrolyte and under UV irradiation (reprinted from [40] with permission, Copyright Elsevier, 2014).
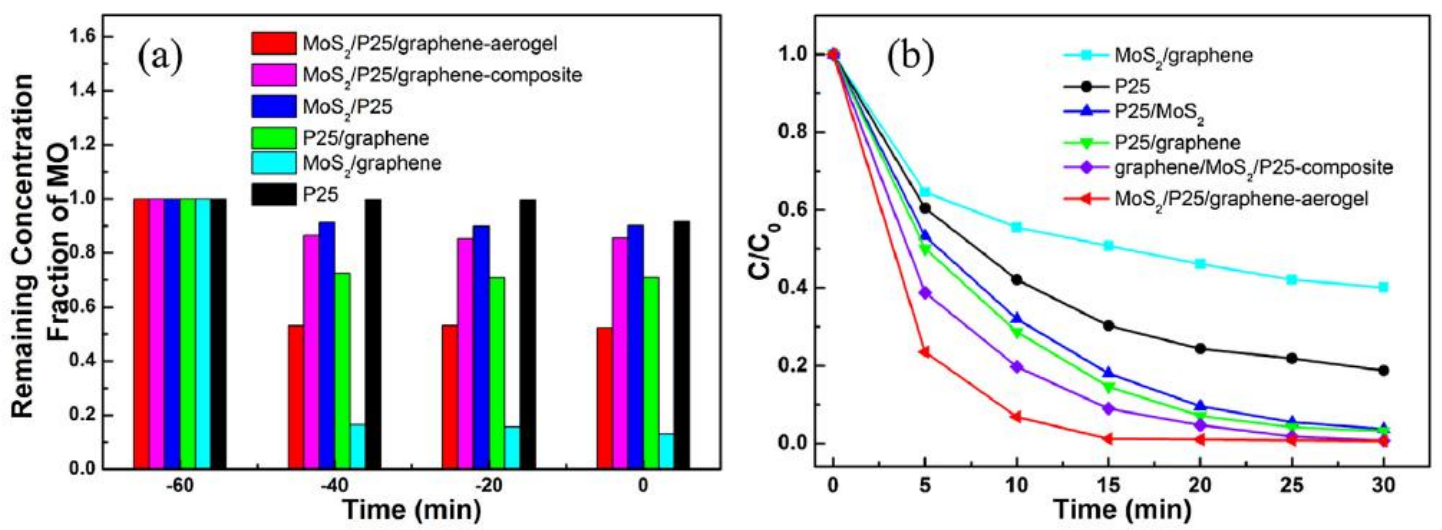

Figure 8. (a) Bar plot showing the remaining methyl orange (MO) in solution after reaching the adsorption equilibrium in the dark over MoS2/P25/GR-aerogel, GR/P25/MoS2-composite, P25/GR, MoS2/P25, MoS2/GR, and P25; (b) photo-degradation of MO by MoS2/P25/GR-aerogel, GR/P25/MoS2-composite, P25/GR, MoS2/P25, MoS2/GR, and P25 with a reaction time of $30 \mathrm{~min}$ under UV irradiation (reprinted from [40] with permission, Copyright Elsevier, 2014).

Gao et al. fabricated a $\mathrm{TiO}_{2}-\mathrm{MoS}_{2} / \mathrm{GR}$ composite under atmospheric pressure using a simple one-pot solvothermal method [34]. $\mathrm{Na}_{2} \mathrm{MoO}_{4}$ and thiocarbamide were used as precursors for $\mathrm{MoS}_{2}$, and mixed solvent of (dimethylacetamide (DMAc)/deionized (DI) $\mathrm{H}_{2} \mathrm{O}$ ) was used as reaction media. Under the above conditions, $\mathrm{MoS}_{2}$ quantum dots (QDs) with (100) face exposed could be generated on the surface of $\mathrm{TiO}_{2}$ and GR (Figure 9). Attributed to the small diameter of the $\mathrm{MoS}_{2}$ QDs, more active edge could be created, thus leading to the enhanced photocatalytic activity.

Peng et al. synthesized $\mathrm{Ag}_{3} \mathrm{PO}_{4}-\mathrm{MoS}_{2} / \mathrm{GR}$ via a simple two-step hydrothermal process [33]. The composite was found to be an effective catalyst for the photo-decomposition of 2,4-dichlorophenol (DCP) under simulated solar light and visible light $(\lambda>420 \mathrm{~nm})$. They described the major reaction steps involved in this photocatalytic process as follows:

$$
\begin{gathered}
\mathrm{Ag}_{3} \mathrm{PO}_{4}+\mathrm{hv} \rightarrow \mathrm{Ag}_{3} \mathrm{PO}_{4}\left(\mathrm{e}^{-}+\mathrm{h}^{+}\right) \\
\mathrm{Ag}_{3} \mathrm{PO}_{4}\left(\mathrm{e}^{-}\right)+\mathrm{MoS}_{2} / \mathrm{GR} \rightarrow \mathrm{Ag}_{3} \mathrm{PO}_{4}+\mathrm{MoS}_{2} / \mathrm{GR}\left(\mathrm{e}^{-}\right) \\
\mathrm{MoS}_{2} / \mathrm{GR}\left(\mathrm{e}^{-}\right)+\mathrm{O}_{2} \rightarrow \mathrm{MoS}_{2} / \mathrm{GR}+\mathrm{O}_{2}{ }^{-}
\end{gathered}
$$




$$
\begin{gathered}
\mathrm{Ag}_{3} \mathrm{PO}_{4}\left(\mathrm{~h}^{+}\right)+\mathrm{DCP} \rightarrow \mathrm{CO}_{2}+\mathrm{H}_{2} \mathrm{O}+\text { other products } \\
\mathrm{Ag}_{3} \mathrm{PO}_{4}\left(\mathrm{~h}^{+}\right)+\mathrm{OH}^{-} \rightarrow \mathrm{Ag}_{3} \mathrm{PO}_{4}+\cdot \mathrm{OH} \\
\cdot \mathrm{OH}+\mathrm{DCP} \rightarrow \mathrm{CO}_{2}+\mathrm{H}_{2} \mathrm{O}+\text { other products }
\end{gathered}
$$

As shown in the mechanism, electrons and holes could be separated with irradiation (1). The holes could oxidize the DCP molecules adsorbed on the catalyst surface directly (4). They could also react with water (or hydroxyl) to form hydroxyl free radicals $(\cdot \mathrm{OH})$, which are strong oxidants for DCP decomposition (5). The $\mathrm{MoS}_{2} / \mathrm{GR}$ cocatalyst here could act as electron collectors to facilitate the interfacial electron transfer and charge separation. In addition, the $\mathrm{MoS}_{2} / \mathrm{GR}$ cocatalyst could also provide more active sites and allow for the activation of dissolved $\mathrm{O}_{2}$ for organic degradation [33].

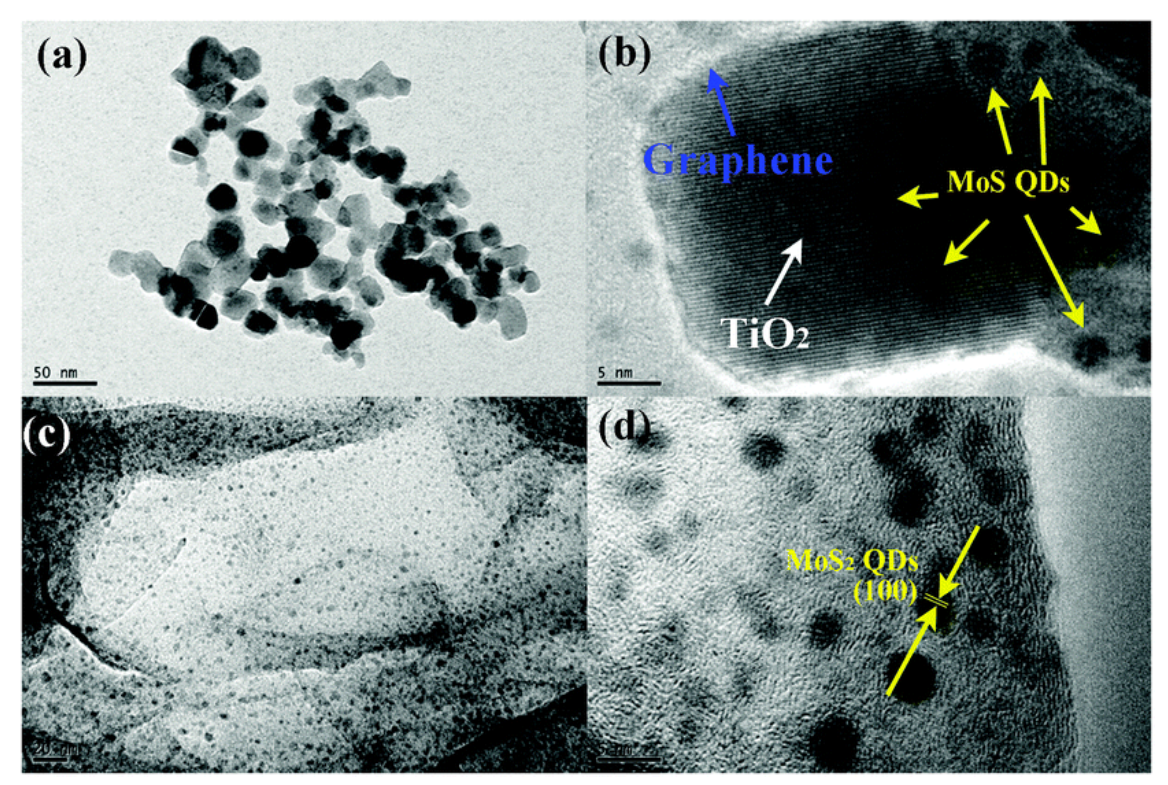

Figure 9. TEM and HRTEM images of the sample (a,b) $\mathrm{TiO}_{2}-\mathrm{MoS}_{2} / \mathrm{GR}$ and (c,d) $\mathrm{MoS}_{2}-\mathrm{GR}$ (reprinted from [34] with permission, Copyright Royal Society of Chemistry, 2015). QD: quantum dot.

Using $\mathrm{CoS}_{2} / \mathrm{GR}$ as cocatalyst, $\mathrm{Zhu}$ et al. supported $\mathrm{TiO}_{2}$ nanoparticles on its surface using a facile sonochemical and hydrothermal method [35]. Their photo-activity was then evaluated for the degradation of methylene blue (MB) and Texbrite BA-L (TBA) under visible light. Enhanced activity was obtained due to the synergetic effect between $\mathrm{TiO}_{2}$ and the $\mathrm{CoS}_{2} / \mathrm{GR}$ cocatalyst. The recent progress of TMD/GR based photocatalysts for $\mathrm{H}_{2}$ evolution and pollutants degradation are summarized and shown in Table 1 for a easier perusal. 
Table 1. Summary of transition metal dichalcogenides (TMD)/GR based photocatalysts and their applications.

\begin{tabular}{|c|c|c|c|c|c|c|}
\hline Catalyst & Synthesis Method & Application & Light Source & Activity & Morphology & Ref. \\
\hline $\mathrm{TiO}_{2}-\mathrm{MoS}_{2} / \mathrm{GR}$ & Two-step hydrothermal & $\begin{array}{c}\mathrm{H}_{2} \text { generation } \\
\text { in 25\% }(v / v) \text { ethanol/water }\end{array}$ & $\begin{array}{c}350 \mathrm{~W} \text { Xe arc lamp } \\
20 \mathrm{~mW} / \mathrm{cm}^{-2} \\
\lambda=365 \mathrm{~nm}\end{array}$ & $\begin{array}{c}165.3 \mu \mathrm{mol} \cdot \mathrm{h}^{-1} \\
{ }^{\mathrm{a}} \mathrm{QE}: 9.7 \% \\
\text { at } 365 \mathrm{~nm}\end{array}$ & Particles/sheets & [25] \\
\hline $\mathrm{CdS}^{-\mathrm{MoS}_{2} / \mathrm{GR}}$ & Hydrothermal & $\begin{array}{l}\mathrm{H}_{2} \text { generation in } 20 \mathrm{vol} \% \\
\text { lactic solution }\end{array}$ & $300 \mathrm{~W}$ Xe lamp $(\lambda>420 \mathrm{~nm})$ & $\begin{array}{l}1.8 \mathrm{mmol} / \mathrm{h} \\
\text { QE: } 28.1 \% \\
\text { at } 420 \mathrm{~nm}\end{array}$ & Particles/sheets & [27] \\
\hline $\mathrm{CdS}-\mathrm{MoS}_{2} / \mathrm{GR}$ & $\begin{array}{l}\text { Sonication assisted } \\
\text { post loading }\end{array}$ & $\begin{array}{c}\mathrm{H}_{2} \text { generation in } 10 \mathrm{vol} \% \\
\text { lactic acid }\end{array}$ & 500 W UV-vis lamp & $3.067 \mathrm{~mL} \cdot \mathrm{h}^{-1}$ & Particles/sheets & [28] \\
\hline $\mathrm{CdS}-\mathrm{MoS}_{2} / \mathrm{GR}$ & $\begin{array}{l}\text { In-situ } \\
\text { photo deposition }\end{array}$ & $\begin{array}{l}\mathrm{H}_{2} \text { generation in } 10 \mathrm{vol} \% \\
\text { lactic acid }\end{array}$ & $\begin{array}{c}350 \mathrm{~W} \text { Xe lamp } \\
\lambda \geq 420 \mathrm{~nm} \\
34 \mathrm{~mW} / \mathrm{cm}^{2}\end{array}$ & $\begin{array}{l}99 \mu \mathrm{mol} \cdot \mathrm{h}^{-1} \\
\text { QE: } 9.8 \% \\
\text { at } 420 \mathrm{~nm}\end{array}$ & Particles/sheets & [29] \\
\hline ZnS-MoS 2 /GR & One-pot hydrothermal & $\begin{array}{l}\mathrm{H}_{2} \text { generation in } 0.005 \mathrm{M} \\
\mathrm{Na}_{2} \mathrm{~S} \text { and } 0.005 \mathrm{M} \mathrm{Na}_{2} \mathrm{SO}_{3}\end{array}$ & $\begin{array}{l}300 \mathrm{~W} \text { Xe lamp } \\
125 \mathrm{~mW} / \mathrm{cm}^{2}\end{array}$ & $2258 \mu \mathrm{mol} \cdot \mathrm{h}^{-1} \cdot \mathrm{g}^{-1}$ & Particles/sheets & [30] \\
\hline $\mathrm{CdS}^{-\mathrm{MoS}_{2} / \mathrm{GR}}$ & Two-step solvothermal & $\begin{array}{c}\mathrm{H}_{2} \text { generation in } 10 \mathrm{vol} \% \\
\text { lactic acid }\end{array}$ & $\begin{array}{l}350 \mathrm{~W} \text { xenon arc lamp } \\
(\lambda \geq 420 \mathrm{~nm})\end{array}$ & $\begin{array}{c}621.3 \mu \mathrm{mol} \cdot \mathrm{h}^{-1} \\
54.4 \% \\
\text { at } 420 \mathrm{~nm}\end{array}$ & Nanorods / sheets & [31] \\
\hline $\mathrm{CdS}-\mathrm{WS}_{2} / \mathrm{GR}$ & Solvothermal & $\begin{array}{l}\mathrm{H}_{2} \text { generation in } 0.35 \mathrm{M} \\
\mathrm{Na}_{2} \mathrm{~S} \text { and } 0.25 \mathrm{M} \mathrm{Na}_{2} \mathrm{SO}_{3}\end{array}$ & $\begin{array}{c}500 \mathrm{~W} \text { Xeno arc Lamp } \\
\lambda>420 \mathrm{~nm}\end{array}$ & $\begin{array}{l}1842 \mu \mathrm{mol} \cdot \mathrm{h}^{-1} \cdot \mathrm{g}^{-1} \\
21.2 \% \text { at } 420 \mathrm{~nm}\end{array}$ & Nanosheets/nanorods & [32] \\
\hline $\mathrm{Ag}_{3} \mathrm{PO}_{4}-\mathrm{MoS}_{2} / \mathrm{GR}$ & Hydrothermal-deposition & $\begin{array}{c}\text { 2,4-Dichlorophenol } \\
\text { degradation } 20 \mathrm{mg} \cdot \mathrm{L}^{-1}\end{array}$ & $\begin{array}{l}500 \mathrm{~W} \text { xenon lamp } \\
(\lambda>420 \mathrm{~nm})\end{array}$ & $\begin{array}{c}{ }^{\mathrm{b}} \mathrm{DP} \text { of }>99 \% \text { in } 20 \mathrm{~min} \\
25 \text { times higher than } \mathrm{N}-\mathrm{TiO}_{2}\end{array}$ & Sub-microcrystal/sheets & [33] \\
\hline $\mathrm{TiO}_{2}-\mathrm{MoS}_{2} / \mathrm{GR}$ & One-pot solvothermal & $\mathrm{RhB}$ degradation $10 \mathrm{mg} \cdot \mathrm{L}^{-1}$ & 150 W Xe lamp & $\begin{array}{l}\text { DP of } 80 \% \text { in } 80 \mathrm{~min} \\
\text { 3.9 times higher than } \mathrm{TiO}_{2} \text { P25 }\end{array}$ & Sheets/Particles & [34] \\
\hline $\mathrm{TiO}_{2}-\mathrm{CoS}_{2} / \mathrm{GR}$ & $\begin{array}{l}\text { Sonochemical and } \\
\text { hydrothermal method }\end{array}$ & $\begin{array}{l}\text { MB degradation } \\
2.0 \times 10^{-5} \mathrm{~mol} / \mathrm{L}\end{array}$ & $\begin{array}{l}8 \mathrm{~W} \text {, halogen lamp } \\
400-790 \mathrm{~nm} .\end{array}$ & $\mathrm{DP}$ of $>90 \%$ in $90 \mathrm{~min}$ & Sheets/Particles & [35] \\
\hline
\end{tabular}

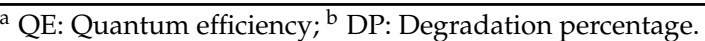




\section{Conclusions and Perspective}

This mini review focused on the recent developments of the TMD/GR-based composites, including the synthesis methods, the application in photocatalytic $\mathrm{H}_{2}$ evolution, and the application for organic pollutants degradation. By combination with GR, the TMD/GR hybrids were more effective as cocatalysts for the modification of semiconductors. GR here can act as a conductive electron transport "highway" for the transport of the photogenerated electrons, and the TMDs nanosheets in the hybrids can accept electrons and act as active sites for photocatalytic reactions. Although deep research is still needed for real application, TMD/GR cocatalysts have shown great potential as a platform to fabricate more efficient photocatalysts for solar energy utilization.

Acknowledgments: This research was supported by the project No. 21506158 from the National Natural Science Foundation of China (NSFC).

Conflicts of Interest: The authors declare no conflict of interest.

\section{References}

1. Inoue, T.; Fujishima, A.; Konishi, S.; Honda, K. Photoelectrocatalytic Reduction of Carbon Dioxide in Aqueous Suspensions of Semiconductor Powders. Nature 1979, 277, 637-638. [CrossRef]

2. Rajeshwar, K.; De Tacconi, N.R. Solution Combustion Synthesis of Oxide Semiconductors for Solar Energy Conversion and Environmental Remediation. Chem. Soc. Rev. 2009, 7, 1984-1998. [CrossRef] [PubMed]

3. Kudo, A.; Miseki, Y. Heterogeneous Photocatalyst Materials for Water Splitting. Chem. Soc. Rev. 2009, 1, 253-278. [CrossRef] [PubMed]

4. Perera, S.D.; Mariano, R.G.; Vu, K.; Nour, N.; Seitz, O.; Chabal, Y.; Balkus, K.J. Hydrothermal Synthesis of Graphene- $\mathrm{TiO}_{2}$ Nanotube Composites with Enhanced Photocatalytic Activity. Acs. Catal. 2012, 6, 949-956. [CrossRef]

5. Li, P.; Wei, Z.; Wu, T.; Peng, Q.; Li, Y.D. Au-Zno Hybrid Nanopyramids and Their Photocatalytic Properties. J. Am. Chem. Soc. 2011, 15, 5660-5663. [CrossRef]

6. Liu, Y.; Yu, Y.X.; Zhang, W.D. $\mathrm{MoS}_{2}$ /CdS Heterojunction with High Photoelectrochemical Activity for $\mathrm{H}_{2}$ Evolution under Visible Light: The Role of $\mathrm{MoS}_{2}$. J. Phys. Chem. C 2013, 25, 12949-12957. [CrossRef]

7. Zou, X.X.; Zhang, Y. Noble Metal-Free Hydrogen Evolution Catalysts for Water Splitting. Chem. Soc. Rev. 2015, 15, 5148-5180. [CrossRef] [PubMed]

8. Lu, Q.P.; Yu, Y.F.; Ma, Q.L.; Chen, B.; Zhang, H. 2D Transition-Metal-Dichalcogenide-Nanosheet-Based Composites for Photocatalytic and Electrocatalytic Hydrogen Evolution Reactions. Adv. Mater. 2016, 10, 1917-1933. [CrossRef] [PubMed]

9. Chang, K.; Hai, X.; Ye, J.H. Transition Metal Disulfides as Noble-Metal-Alternative Co-Catalysts for Solar Hydrogen Production. Adv. Energy Mater. 2016, 10. [CrossRef]

10. Bhandavat, R.; David, L.; Singh, G. Synthesis of Surface-Functionalized $\mathrm{WS}_{2}$ nanosheets and Performance as Li-Ion Battery Anodes. J. Phys. Chem. Lett. 2012, 11, 1523-1530. [CrossRef] [PubMed]

11. Gong, Q.F.; Cheng, L.; Liu, C.H.; Zhang, M.; Feng, Q.L.; Ye, H.L.; Zeng, M.; Xie, L.M.; Liu, Z.; Li, Y.G. Ultrathin $\mathrm{MoS}_{2(1-x)} \mathrm{Se}_{2 x}$ alloy Nanoflakes for Electrocatalytic Hydrogen Evolution Reaction. ACS Catal. 2015, 4, 2213-2219. [CrossRef]

12. Prabakaran, A.; Dillon, F.; Melbourne, J.; Jones, L.; Nicholls, R.J; Holdway, P.; Britton, J.; Koos, A.A.; Crossley, A.; Nellist, P.D.; et al. WS 2 2D Nanosheets in 3D Nanoflowers. Chem. Commun. (Camb.) 2014, 82, 12360-12362. [CrossRef] [PubMed]

13. Lee, S.C.; Benck, J.D.; Tsai, C.; Park, J.; Koh, A.L.; Abild-Pedersen, F.; Jaramillo, T.F.; Sinclair, R. Chemical and Phase Evolution of Amorphous Molybdenum Sulfide Catalysts for Electrochemical Hydrogen Production. ACS NANO 2016, 1, 624-632. [CrossRef] [PubMed]

14. Baldovi, H.G.; Latorre-Sanchez, M.; Esteve-Adell, I.; Khan, A.; Asiri, A.M.; Kosa, S.A.; Garcia, H. Generation of $\mathrm{MoS}_{2}$ Quantum Dots by Laser Ablation of $\mathrm{MoS}_{2}$ Particles in Suspension and Their Photocatalytic Activity for $\mathrm{H}_{2}$ Generation. J. Nanoparticle Res. 2016, 8, 240. [CrossRef]

15. Zong, X.; Yan, H.J.; Wu, G.P.; Ma, G.J.; Wen, F.Y.; Wang, L.; Li, C. Enhancement of Photocatalytic $\mathrm{H}_{2}$ Evolution on CdS by Loading $\mathrm{MoS}_{2}$ as Cocatalyst under Visible Light Irradiation. J. Am. Chem. Soc. 2008, 23, 7176-7177. [CrossRef] [PubMed] 
16. Bai, S.; Wang, L.M.; Chen, X.Y.; Du, J.T.; Xiong, Y.J. Chemically exfoliated metallic $\mathrm{MoS}_{2}$ nanosheets: A promising supporting Co-catalyst for enhancing the photocatalytic performance of $\mathrm{TiO}_{2}$ nanocrystals. Nano Res. 2015, 1, 175-183. [CrossRef]

17. Morales-Guio, C.G.; Stern, L.A.; Hu, X.L. Nanostructured hydrotreating catalysts for electrochemical hydrogen evolution. Chem. Soc. Rev. 2014, 18, 6555-6569. [CrossRef] [PubMed]

18. Morales-Guio, C.G.; Hu, X.L. Amorphous molybdenum sulfides as hydrogen evolution catalysts. Accounts Chem. Res. 2014, 8, 2671-2681. [CrossRef] [PubMed]

19. Yan, Y.; Xia, B.Y.; Xu, Z.C.; Wang, X. Recent development of molybdenum sulfides as advanced electrocatalysts for hydrogen evolution reaction. Acs Catal. 2014, 6, 1693-1705. [CrossRef]

20. Zhang, J.; Zhu, Z.P.; Feng, X.L. Construction of two-dimensional $\mathrm{MoS}_{2} / \mathrm{CdS}$ p-n nanohybrids for highly efficient photocatalytic hydrogen evolution. Chem.-A Eur. J. 2014, 34, 10632-10635. [CrossRef] [PubMed]

21. Zhu, Y.Y.; Ling, Q.; Liu, Y.F.; Wang, H.; Zhu, Y.F. Photocatalytic $\mathrm{H}_{2}$ evolution on $\mathrm{MoS}_{2}-\mathrm{TiO}_{2}$ catalysts synthesized via mechanochemistry. Phys. Chem. Chem. Phys. 2015, 2, 933-940. [CrossRef] [PubMed]

22. Vattikuti, S.P.; Byon, C.; Reddy, C.V.; Ravikumar, R.V. Improved photocatalytic activity of $\mathrm{MoS}_{2}$ nanosheets decorated with $\mathrm{SnO}_{2}$ nanoparticles. Rsc Adv. 2015, 105, 86675-86684. [CrossRef]

23. Novoselov, K.S.; Geim, A.K.; Morozov, S.V.; Jiang, D.; Zhang, Y.; Dubonos, S.V.; Grigorieva, I.V.; Firsov, A.A. Electric field effect in atomically thin carbon films. Science 2004, 5696, 666-669. [CrossRef] [PubMed]

24. Peng, W.C.; Li, X.Y. Synthesis of a sulfur-graphene composite as an enhanced metal-free photocatalyst. Nano Res. 2013, 4, 286-292. [CrossRef]

25. Xiang, Q.J.; Yu, J.G.; Jaroniec, M. Synergetic effect of $\mathrm{MoS}_{2}$ and graphene as cocatalysts for enhanced photocatalytic $\mathrm{H}_{2}$ production activity of $\mathrm{TiO}_{2}$ nanoparticles. J. Am. Chem. Soc. 2012, 15, 6575-6578. [CrossRef] [PubMed]

26. Liu, G.; Zhao, Y.; Sun, C.; Li, F.; Lu, G.Q.; Cheng, H.-M. Synergistic effects of B/N doping on the visible-light photocatalytic activity of mesoporous $\mathrm{TiO}_{2}$. Angew. Chem.-Int. Ed. 2008, 24, 4516-4520. [CrossRef] [PubMed]

27. Chang, K.; Mei, Z.W.; Wang, T.; Kang, Q.; Ouyang, S.X.; Ye, J.H. $\mathrm{MoS}_{2}$ /graphene cocatalyst for efficient photocatalytic $\mathrm{h}_{2}$ evolution under visible light irradiation. Acs NANO 2014, 7, 7078-7087. [CrossRef] [PubMed]

28. Jia, T.T.; Kolpin, A.; Ma, C.S.; Chan, R.C.T.; Kwok, W.M.; Tsang, S.C.E. A Graphene dispersed CdS-MoS 2 nanocrystal ensemble for cooperative photocatalytic hydrogen production from water. Chem. Commun. 2014, 10, 1185-1188. [CrossRef] [PubMed]

29. Li, Y.X.; Wang, H.; Peng, S.Q. Tunable Photodeposition of $\mathrm{MoS}_{2}$ onto a Composite of Reduced Graphene Oxide and Cds for Synergic Photocatalytic Hydrogen Generation. J. Phys. Chem. C 2014, 34, 19842-19848. [CrossRef]

30. Zhu, B.L.; Lin, B.Z.; Zhou, Y.; Sun, P.; Yao, Q.R.; Chen, Y.L.; Gao, B.F. Enhanced photocatalytic $\mathrm{H}_{2}$ evolution on Zns loaded with graphene and $\mathrm{MoS}_{2}$ nanosheets as cocatalysts. J. Mater. Chem. A 2014, 11, 3819-3827. [CrossRef]

31. Lang, D.; Shen, T.T.; Xiang, Q.J. Roles of $\mathrm{MoS}_{2}$ and graphene as cocatalysts in the enhanced visible-light photocatalytic $\mathrm{H}_{2}$ production activity of multiarmed CdS nanorods. Chemcatchem 2015, 6, 943-951. [CrossRef]

32. Xiang, Q.J.; Cheng, F.Y.; Lang, D. Hierarchical layered $\mathrm{WS}_{2}$ /graphene-modified CdS nanorods for efficient photocatalytic hydrogen evolution. Chemsuschem 2016, 9, 996-1002. [CrossRef] [PubMed]

33. Peng, W.C.; Wang, X.; Li, X.Y. The synergetic effect of $\mathrm{MoS}_{2}$ and graphene on $\mathrm{Ag}_{3} \mathrm{PO}_{4}$ for its ultra-enhanced photocatalytic activity in phenol degradation under visible light. Nanoscale 2014, 14, 8311-8317. [CrossRef] [PubMed]

34. Gao, W.Y.; Wang, M.Q.; Ran, C.X.; Li, L. Facile one-pot synthesis of $\mathrm{MoS}_{2}$ quantum dots-graphene-TiO composites for highly enhanced photocatalytic properties. Chem. Commun. 2015, 9, 1709-1712. [CrossRef] [PubMed]

35. Zhu, L.; Jo, S.B.; Ye, S.; Ullah, K.; Meng, Z.D.; Oh, W.C. A Green and direct synthesis of photosensitized $\mathrm{CoS}_{2}$-graphene/ $\mathrm{TiO}_{2}$ hybrid with high photocatalytic performance. J. Ind. Eng. Chem. 2015, 22, $264-271$. [CrossRef]

36. Wang, G.M.; Yang, X.Y.; Qian, F.; Zhang, J.Z.; Li, Y. Double-sided cds and cdse quantum dot co-sensitized $\mathrm{ZnO}$ nanowire arrays for photoelectrochemical hydrogen generation. NANO Lett. 2010, 3, 1088-1092. [CrossRef] [PubMed] 
37. Li, L.; Yan, J.; Wang, T.; Zhao, Z.-J.; Zhang, J.; Gong, J.; Guan, N. Sub-10 nm rutile titanium dioxide nanoparticles for efficient visible-light-driven photocatalytic hydrogen production. Nat. Commun. 2015, 6. [CrossRef] [PubMed]

38. Yan, H.; Yang, J.; Ma, G.; Wu, G.; Zong, X.; Lei, Z.; Shi, J.; Li, C. Visible-light-driven hydrogen production with extremely high quantum efficiency on Pt-PdS/CdS photocatalyst. J. Catal. 2009, 2, 165-168. [CrossRef]

39. Hoffmann, M.R.; Martin, S.T.; Choi, W.Y.; Bahnemann, D.W. Environmental applications of semiconductor photocatalysis. Chem. Rev. 1995, 1, 69-96. [CrossRef]

40. Han, W.J.; Zang, C.; Huang, Z.Y.; Zhang, H.; Ren, L.; Qi, X.; Zhong, J.X. Enhanced photocatalytic activities of three-dimensional graphene-based aerogel embedding $\mathrm{TiO}_{2}$ nanoparticles and loading $\mathrm{MoS}_{2}$ nanosheets as Co-catalyst. Int. J. Hydrog. Energy 2014, 34, 19502-19512. [CrossRef]

(C) 2017 by the authors. Licensee MDPI, Basel, Switzerland. This article is an open access article distributed under the terms and conditions of the Creative Commons Attribution (CC BY) license (http:/ / creativecommons.org/licenses/by/4.0/). 